\title{
Tax Arrangement and Regional Industrial Restructuring: Evidence from Panel Data in China
}

\author{
Jinying Ma, ${ }^{1}$ Xi Zhang, ${ }^{2,3}$ Feng Tao, ${ }^{4}$ and Fuzheng Luo ${ }^{5}$ \\ ${ }^{1}$ School of Business, Hunan Normal University, Changsha 410006, China \\ ${ }^{2}$ Institute of Policy and Management, Chinese Academy of Sciences, Beijing 100190, China \\ ${ }^{3}$ Business School, Hunan First Normal University, Changsha 410205, China \\ ${ }^{4}$ Institute of Industrial Economics, Jinan University, Guangzhou 510632, China \\ ${ }^{5}$ School of Economics and Trade, Hunan University, Changsha 410079, China
}

Correspondence should be addressed to Xi Zhang; zhangxi@hnu.edu.cn

Received 2 February 2016; Accepted 5 May 2016

Academic Editor: Juan C. Agüero

Copyright (C) 2016 Jinying Ma et al. This is an open access article distributed under the Creative Commons Attribution License, which permits unrestricted use, distribution, and reproduction in any medium, provided the original work is properly cited.

\begin{abstract}
Regional industrial restructuring has been one of the major items in the transformation of economic development mode. An exploration was made into the influence of tax arrangement on the regional industrial structure by setting up a panel data econometric model based on the evaluation and analysis of the regional industrial structure in China. It was shown that tax arrangement influenced the regional industrial restructuring in terms of three aspects. Microlevel: the turnover tax and income tax appeared with a $U$-path of influence on upgrading of the industrial structure while appearing with an inverted U-path of influence on rationalization of the industrial structure. In addition, the levy of resource tax had a negative impact on both upgrading and rationalization of the industrial structure. Mesolevel: taxation in the secondary and tertiary industries appeared with a U-path of influence on upgrading of the industrial structure. An increase of taxation in the secondary industry had a negative impact on rationalization of the industrial structure. The taxation in the tertiary industry appeared with an inverted U-path of influence on rationalization of the industrial structure. Macrolevel: the macrotax burden had a U-path of influence on both upgrading and rationalization of the industrial structure.
\end{abstract}

\section{Introduction}

The rationalization of industrial structure is directly correlated to the speed of economic growth and the quality of economic development. The basis task of transforming the economic development mode is to adjust and optimize the economic structure and turn the low-level and unbalanced economic structure to an upgraded and balanced one. The transformation of economic structure involves several aspects of the economic system including the pattern of ownership, production, demand, and market structure, among which the industrial structure is the most fundamental, the most important, and the most representative one that mainly reflects the requirement and the level of economic restructuring.

The extensive economic development mode has led to increasingly acute unreasonable problems in the economic structure in China including low-level and unbalanced structure, which has become the fundamental problem while enabling rapid economic growth in China since the reform and opening up. These problems have turned a structural reform of the economy in China and transformation of the economic development mode with great effects to a must. However, in the structural reform strategy in domestic economy, adjustment of the industrial structure is the most fundamental and the most important point and concentrated embodiment of the economic restructuring.

Tax arrangement is a variable with great significance among these factors restricting the regional industrial restructuring. Taxation is one of the major instruments taken by the government to regulate economy. The preferential tax policy implemented by the government in the 1980s plays an important role in domestic economic development especially in terms of foreign investment attraction and development 
of high-tech industries. In the 1990s, China initiated the tax reform to further promote the adjustment of the industrial structure in China. However, transformation of current economic development direction and industrial structure in China leads to the fact that existing tax arrangement is not fully applicable to the adjustment of existing regional industrial structure in China.

For this reason, the effect of tax arrangement on the regional industrial structure is discussed by empirical study in terms of the economically structural transformation and based on the evaluation and analysis of the regional industrial structure in China. Existing problems are analyzed to provide cognition foundations for optimized regional industrial structure by improving the tax arrangement.

The remainder of the paper proceeds as follows: the literature review is given in Section 2; an evaluation and analysis of the regional industrial restructuring in China is included in Section 3; design of empirical study is described in Section 4; analysis of the empirical study results is given in Section 5; and the last section is the conclusions.

\section{Literature Review}

Countries all over the world have realized that tax incentives are important means of guiding additional business investment and industrial structure adjustment in practices. As Zee et al. [1] put it, tax incentives have been widely used in various industrial policies especially in developing countries. Several literatures have studied the problem. For example, Salinger and Summers [2] selected the data of 30 Dow Jones business enterprises for follow-up survey. They came to the finding that reduction of tax burden on business enterprises and provision of preferential tax policies promoted voluntary investment by enterprises. Rajagopal and Shah [3] analyzed the tax policy in textile, chemical, and pharmaceutical industries in Pakistan. They found that certain tax preference contributed to both optimizing and upgrading of the industrial structure in the region. EU countries also promoted green power development with different tax incentives [4].

Tax policies affect the industrial structure with various approaches. It is generally recognized that, in terms of supply, tax policies affect supply including the number and quality of labor forces, capital quantity, and technology progress and further affect the industrial structure in the country and regions [5]. For demand, tax policies have an effect on total demand by affecting the consumption structure, investment demand, and proportions of both, leading to transmission of such change to a change of the industrial structure and realization of upgrading and optimization of the industrial structure [6]. Ren et al. [7] analyzed the effect of sulfur tax levy on the industrial structure in Liaoning by CGE model, indicating that sulfur tax contributed to changing the demand preference of consumers, reducing the requirements of fossil requirements and speeding up transfer of capital and labor forces to the tertiary industry, and promoting the adjustment of industrial structure. A case study demonstrates existence of this approach. In addition, tax policies have an effect on enterprise costs and change its profitability, thus affecting the scale of the whole industry and the market. Inconsistent tax policies in the industries may lead to direct changes of the whole industrial structure. This is a direct way by which tax policies affect the industrial structure $[8,9]$.

China has undergone a major period during which its economy receives rapid development over the past 30 years $[10,11]$. However, key "deficiencies" are generated in such process, including structural problem of economic development. An unbalanced and inconsistent industrial structure is the embodiment of such "deficiency" of the economic structure. Such embodiment consists of two aspects: (1) "quality" of the structure: extensive industrial development mode with high energy consumption, material consumption and pollution, and low labor cost, resource cost, environment cost and technology content, and price competition; (2) "quantity" of the structure: proportion of the industrial structure, such as the proportion of high-tech industries.

Giving the restrictions of both "quality" and "quantity" of existing industrial structure by both resources/environment and costs/prices as well as the international market, it is very vulnerable to the impact of the international financial turmoil. The industrial structure will be greatly optimized in terms of the "quality" and the "quantity" by actively promoting high gradation and reasonableness of the industrial structure with policy implementation by the government and market drives.

Chinese government has also made efforts to it: since 2008, China has formulated and implemented the restructuring and rejuvenation program in key industries where rejuvenation is focused on and importance is attached to restructuring. It is required that the total capacity should be strictly controlled; outdated capacity should be eliminated; and encouragement should be given to independent innovation, technological transformation, merging and reorganization, optimized arrangement, and so forth. This is not only a major initiative of the "package" program as a response to the international financial crisis but also a strategic choice of transforming the economic development mode in view of upgrading and rationalization of the industrial structure [12].

With industrial upgrading and independent innovation, the implementation of industrial strategies has led to positive results over China: low-level industrial enterprises with low competitiveness, high resource consumption rate, and heavy pollution are "eliminated" by the market; and innovation becomes the central power of industrial development and also the directional force of industrial restructuring and source of economic growth. The "quality" of industrial structure is the drive of industrial restructuring. A change in the "quality" of industrial structure optimizes its "quantity."

\section{Evaluation and Analysis of Regional Industrial Restructuring in China}

It is necessary to evaluate the regional industrial restructuring in China before the effect of tax arrangement on Chinese regional industrial restructuring is discussed so as to analyze the development of regional industrial structure in China. 
3.1. Measure of Regional Industrial Structure Adjustment. Regional industrial restructuring relates to two aspects: upgrading of industrial structure and harmonization of industrial structure correlation. The former analyzes the development of industrial structure while the latter analyzes the harmony between the industrial structure and the input of production factors. For this reason, the regional industrial restructuring is classified into upgrading and rationalization of the industrial structure in this section with reference to the study of Gan et al. [13].

3.1.1. Upgrading of Industrial Structure. Upgrading of industrial structure (denoted by IDH) refers to a process where the industrial structure system is transformed from a lower level to a higher level. Today, the primary industry is still an integral and key factor in the industrial development. However, with the guiding of economic servicing, the primary industry cannot reflect the evolvement process where the industrial structure is upgraded. In contrast, the tendency of the secondary and the tertiary industries is the more important sign, especially the tendency of the tertiary industry. Wu Jinglian wrote in his book titled the Choice of Chinese Growth Model that a typical case in the "economic servicing" process is that the growth rate of the tertiary industry is higher than that of the secondary industry. On this basis, the index of industrial structure upgrading is designed as follows:

$$
\mathrm{IDH}_{i t}=\frac{Y_{i t}^{3}}{Y_{i t}^{2}},
$$

where $\mathrm{IDH}_{i t}$ denotes the degree of upgrading of the industrial structure in region $t$ in year $i$. $Y_{i t}^{3}$ and $Y_{i t}^{2}$ denote the output values of the tertiary industry and the secondary industry in region $t$ in year $i$, respectively.

3.1.2. Rationalization of Industrial Structure. Rationalization of industrial structure (denoted by IDR) refers to an industrial structure that the industries are mutually coordinated with each other while also being strong in the transformation of its structure and have great adaptability, able to adapt to the changing market demands and bring maximum benefits. It is expressed in the process that the relations of quantity proportion, connection of economy and technology, and interactions among the industries tend to be consistent and balanced. IDR is mainly expressed in the utilization of input of production factors into industrial development. This index is designed based on the degree of harmony between the structure of factor input and the industrial structure. For this reason, the treated structural deviation $(E)$ is used in this section for measurement of IDR. The formula of measurement is as follows:

$$
\begin{aligned}
E_{i t} & =\sum_{k=1}^{3}\left|\frac{Y_{i t}^{k} / L_{i t}^{k}}{Y_{i t} / L_{i t}}-1\right|=\sum_{k=1}^{3}\left|\frac{Y_{i t}^{k} / Y_{i t}}{L_{i t}^{k} / L_{i t}}-1\right| \\
\mathrm{IDR}_{i t} & =\frac{1}{E_{i t}},
\end{aligned}
$$

where $Y$ denotes the output value. $L$ denotes employment. $k=1,2,3$ denotes the primary, the secondary, and

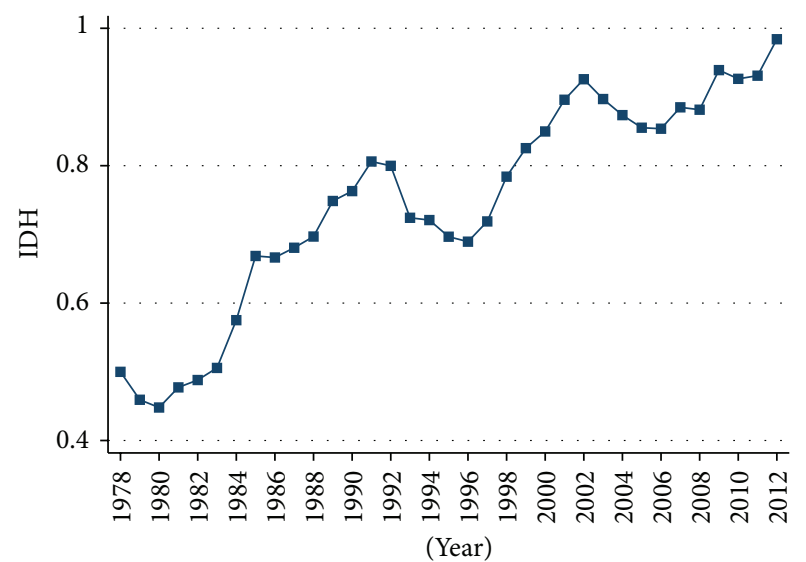

FIgURE 1: Upgrading of the industrial structure in China from 1978 to 2012 .

the tertiary industries. $i$ and $t$ denote the year and the region of the sample. In view of the classical economics hypothesis, economy is finally under balance and industrial sectors have the same level of productivity, defining that $Y / L$ denotes productivity. When the economy is in balance, $Y^{k} / L^{k}=Y / L$, and $E=0$. In addition, $Y^{k} / Y$ denotes the output structure; $L^{k} / L$ denotes the employment structure. Therefore, $E$ is an embodiment of the interaction of output structure and employment structure. $E$ is no less than 0 . The smaller the value is, the higher the degree of harmony between the structure of input factors and the industrial structure will be and the higher the rationalization of industrial structure will be. The bigger the value is, the more obvious the deviation of the industrial structure from balance will be and the higher the degree of irrationality of the industrial structure will be. The value of IDR is calculated by inversing $E$ so that the data appears in a forward direction.

3.2. Evaluation of Regional IDH. China is a large country, and each region (the eastern, central, and western) contains many provinces; however, the heterogeneity among different provinces is obvious. So, in this paper, we use provincial data to calculate the regional IDH and IDR. The degree of the industrial structure upgrading in 31 provinces (municipalities and autonomous regions) from 2003 to 2012 in China is calculated in terms of space and time in the way defined in Section 3.1. The results of calculation are shown in Table 1.

Upgrading of the industrial structure in China from 1978 to 2012 is generally described to figure out the overall progress of industrial structure upgrading in China, as shown in Figure 1.

Despite short-term repetition, the evolution of upgrading of the industrial structure in China generally comes with constant rise, contributing to a quite obvious servicing trend of the industrial structure. Market activity received constant improvement at the beginning of the reform and opening up. The degree of industrial structure upgrading in China gained a quick increase from 0.5 to 0.8 in the beginning of the 1990s. In the 1990s, investment promotion was continued, leading to rapid development of the secondary industry and 
TABLE 1: Regional IDH from 2003 to 2012 in China.

\begin{tabular}{|c|c|c|c|c|c|c|c|c|c|c|}
\hline \multirow{2}{*}{ Province } & \multicolumn{10}{|c|}{ Year } \\
\hline & 2003 & 2004 & 2005 & 2006 & 2007 & 2008 & 2009 & 2010 & 2011 & 2012 \\
\hline Anhui & 0.8194 & 0.7883 & 0.9848 & 0.9335 & 0.8741 & 0.8021 & 0.7466 & 0.6515 & 0.5988 & 0.5985 \\
\hline Beijing & 1.7194 & 1.5959 & 2.3498 & 2.5467 & 2.6870 & 2.8524 & 3.2145 & 3.1286 & 3.2947 & 3.3676 \\
\hline Fujian & 0.8210 & 0.7880 & 0.7898 & 0.7946 & 0.8128 & 0.7847 & 0.8407 & 0.7777 & 0.7585 & 0.7594 \\
\hline Gansu & 0.7577 & 0.6850 & 0.9389 & 0.8629 & 0.8107 & 0.8439 & 0.8926 & 0.7741 & 0.8259 & 0.8729 \\
\hline Guangdong & 0.7151 & 0.6641 & 0.8464 & 0.8335 & 0.8438 & 0.8327 & 0.9296 & 0.8999 & 0.9112 & 0.9574 \\
\hline Guangxi & 1.0664 & 0.9474 & 1.0939 & 1.0207 & 0.9438 & 0.8822 & 0.8633 & 0.7499 & 0.7045 & 0.7388 \\
\hline Guizhou & 0.8259 & 0.7600 & 0.9478 & 0.9258 & 0.9991 & 0.9774 & 1.2771 & 1.2094 & 1.2675 & 1.2260 \\
\hline Hainan & 1.7957 & 1.6912 & 1.6983 & 1.4608 & 1.3670 & 1.3518 & 1.6882 & 1.6702 & 1.6080 & 1.6651 \\
\hline Hebei & 0.6500 & 0.5961 & 0.6422 & 0.6441 & 0.6439 & 0.6125 & 0.6773 & 0.6653 & 0.6462 & 0.6702 \\
\hline Henan & 0.6354 & 0.5874 & 0.5769 & 0.5534 & 0.5447 & 0.5031 & 0.5178 & 0.4996 & 0.5180 & 0.5493 \\
\hline Heilongjiang & 0.5515 & 0.4944 & 0.6243 & 0.6199 & 0.6640 & 0.6539 & 0.8304 & 0.7420 & 0.7187 & 0.9176 \\
\hline Hubei & 0.7838 & 0.7664 & 0.9352 & 0.9140 & 0.9797 & 0.9241 & 0.8491 & 0.7793 & 0.7383 & 0.7334 \\
\hline Hunan & 1.0913 & 1.0125 & 1.0169 & 0.9788 & 0.9338 & 0.8547 & 0.9500 & 0.8674 & 0.8053 & 0.8227 \\
\hline Jilin & 0.7804 & 0.7380 & 0.8944 & 0.8808 & 0.8182 & 0.7971 & 0.7782 & 0.6904 & 0.6558 & 0.6509 \\
\hline Jiangsu & 0.6729 & 0.6163 & 0.6267 & 0.6407 & 0.6723 & 0.6930 & 0.7341 & 0.7875 & 0.8270 & 0.8671 \\
\hline Jiangxi & 0.8498 & 0.7448 & 0.7363 & 0.6738 & 0.6173 & 0.5872 & 0.6728 & 0.6093 & 0.6136 & 0.6462 \\
\hline Liaoning & 0.8582 & 0.8612 & 0.8027 & 0.7496 & 0.6897 & 0.6187 & 0.7451 & 0.6865 & 0.6714 & 0.7150 \\
\hline Neimenggu & 0.7766 & 0.6556 & 0.8644 & 0.7796 & 0.6893 & 0.6050 & 0.7228 & 0.6610 & 0.6240 & 0.6397 \\
\hline Ningxia & 0.7179 & 0.6507 & 0.8989 & 0.8044 & 0.7514 & 0.6835 & 0.8512 & 0.8485 & 0.8161 & 0.8475 \\
\hline Qinghai & 0.8673 & 0.7965 & 0.8064 & 0.7271 & 0.6760 & 0.6168 & 0.6927 & 0.6324 & 0.5539 & 0.5715 \\
\hline Shandong & 0.6457 & 0.5717 & 0.5574 & 0.5637 & 0.5874 & 0.5856 & 0.6226 & 0.6753 & 0.7233 & 0.7770 \\
\hline Shanxi & 0.6133 & 0.5408 & 0.6646 & 0.6285 & 0.5889 & 0.5557 & 0.7229 & 0.6520 & 0.5969 & 0.6957 \\
\hline Shaanxi & 0.8336 & 0.7564 & 0.7520 & 0.6535 & 0.6438 & 0.5871 & 0.7421 & 0.6774 & 0.6280 & 0.6205 \\
\hline Shanghai & 0.9677 & 0.9412 & 1.0377 & 1.0429 & 1.1286 & 1.1787 & 1.4880 & 1.3623 & 1.4055 & 1.5531 \\
\hline Sichuan & 0.9098 & 0.9189 & 0.9249 & 0.8654 & 0.8256 & 0.7513 & 0.7746 & 0.6954 & 0.6360 & 0.6683 \\
\hline Tianjin & 0.8935 & 0.8137 & 0.7479 & 0.7044 & 0.7079 & 0.6309 & 0.8539 & 0.8757 & 0.8804 & 0.9092 \\
\hline Xizang & 1.9981 & 1.9198 & 2.1985 & 1.9976 & 1.9173 & 1.8974 & 1.7628 & 1.6765 & 1.5449 & 1.5557 \\
\hline Xinjiang & 0.8381 & 0.7379 & 0.7979 & 0.7251 & 0.7568 & 0.6832 & 0.8228 & 0.6816 & 0.6960 & 0.7764 \\
\hline Yunnan & 0.8353 & 0.7921 & 0.9564 & 0.9017 & 0.9034 & 0.9090 & 0.9756 & 0.8973 & 0.9792 & 0.9585 \\
\hline Zhejiang & 0.7541 & 0.7249 & 0.7506 & 0.7413 & 0.7534 & 0.7609 & 0.8329 & 0.8437 & 0.8565 & 0.9056 \\
\hline Chongqing & 0.9587 & 0.8913 & 1.0706 & 1.0425 & 0.9239 & 0.8581 & 0.7175 & 0.6609 & 0.6538 & 0.7522 \\
\hline
\end{tabular}

a downtrend of IDH value. In the middle 1990s, the tertiary industry regained the vigor for development to better serve the development of the tertiary industry structure. Domestic of IDH value is up to 0.98 in 2012.

3.3. Evaluation of Regional IDR. The degree of rationalization of the industrial structure in 31 provinces (municipalities and autonomous regions) from 2003 to 2012 in China is calculated in terms of space and time in the way defined in Section 3.1. The results of calculation are shown in Table 2.

Rationalization of the industrial structure in China from 1978 to 2012 is generally described to figure out the overall progress of industrial structure upgrading in China, as shown in Figure 2.

The degree of rationalization of industrial structure in China tends to rise constantly. In the beginning of the reform and opening up, the regionally restricted production factors in China prevented free circulation of production factors and realization of rational allocation, which led to relatively low rationalization of the industrial structure. After that, more and more loosening market and constantly improved market mechanism contributed to rationalization of the industrial structure that continues to rise. Periodic fluctuations are seen in rationalization of the industrial structure in short term; however, it generally appears in upward tendency. The degree of rationalization of industrial structure is up to 0.699 in 2012.

\section{Design of Empirical Study}

The index variables are chosen to analyze the impact of tax arrangement on the industrial structure to reveal the role of domestic regional tax arrangement in industrial restructuring and analyze existing problems.

4.1. Modeling for Empirical Study. Assuming that the output function of industry $i$ is $Q_{i}=A_{i} K_{i}^{\alpha} L_{i}^{\beta}$, the cost function is $C_{i}=r_{i} K+w_{i} L_{i}, i=1,2,3$. A denotes the technology 
TABLE 2: Regional IDR from 2003 to 2012 in China.

\begin{tabular}{|c|c|c|c|c|c|c|c|c|c|c|}
\hline \multirow{2}{*}{ Province } & \multicolumn{10}{|c|}{ Year } \\
\hline & 2003 & 2004 & 2005 & 2006 & 2007 & 2008 & 2009 & 2010 & 2011 & 2012 \\
\hline Anhui & 0.2094 & 0.1744 & 0.1742 & 0.1584 & 0.1596 & 0.1461 & 0.1239 & 0.1234 & 0.1155 & 0.1020 \\
\hline Beijing & 0.2878 & 0.2966 & 0.6281 & 0.7189 & 0.8322 & 0.7012 & 1.1426 & 1.2444 & 0.6705 & 0.7169 \\
\hline Fujian & 0.1974 & 0.1766 & 0.1650 & 0.1542 & 0.1575 & 0.1513 & 0.1659 & 0.1585 & 0.1186 & 0.0878 \\
\hline Gansu & 0.2783 & 0.2823 & 0.3214 & 0.2652 & 0.2277 & 0.2259 & 0.2001 & 0.1936 & 0.2045 & 0.2025 \\
\hline Guangdong & 0.2399 & 0.2079 & 0.2161 & 0.2111 & 0.2152 & 0.2082 & 0.2031 & 0.1856 & 0.1508 & 0.1237 \\
\hline Guangxi & 0.2432 & 0.2240 & 0.2426 & 0.2456 & 0.2370 & 0.2177 & 0.2045 & 0.2008 & 0.1876 & 0.1738 \\
\hline Guizhou & 0.1065 & 0.1080 & 0.0801 & 0.0866 & 0.0818 & 0.0823 & 0.0674 & 0.0717 & 0.0639 & 0.0479 \\
\hline Hainan & 1.4768 & 1.2044 & 1.2730 & 1.0517 & 0.9566 & 0.8194 & 0.9441 & 0.7831 & 0.6185 & 0.6466 \\
\hline Hebei & 0.1267 & 0.1144 & 0.1191 & 0.1230 & 0.1244 & 0.1218 & 0.1131 & 0.1043 & 0.0891 & 0.0769 \\
\hline Henan & 0.0800 & 0.0714 & 0.0775 & 0.0769 & 0.0834 & 0.0780 & 0.0677 & 0.0680 & 0.0678 & 0.0532 \\
\hline Heilongjiang & 0.9862 & 0.8782 & 1.2104 & 1.1248 & 1.2276 & 1.0038 & 1.2828 & 0.8908 & 0.9302 & 1.4456 \\
\hline Hubei & 0.5218 & 0.5055 & 0.4977 & 0.5331 & 0.3891 & 0.2879 & 0.2759 & 0.2331 & 0.1348 & 0.1390 \\
\hline Hunan & 0.2695 & 0.1437 & 0.1147 & 0.1253 & 0.1086 & 0.1191 & 0.0746 & 0.0753 & 0.0725 & 0.0321 \\
\hline Jilin & 0.4533 & 0.4500 & 0.5785 & 0.5824 & 0.5748 & 0.5322 & 0.5412 & 0.5765 & 0.5254 & 0.5135 \\
\hline Jiangsu & 0.4095 & 0.3767 & 0.3751 & 0.3838 & 0.3611 & 0.3083 & 0.2731 & 0.2619 & 0.2215 & 0.1920 \\
\hline Jiangxi & 0.3660 & 0.3273 & 0.3369 & 0.3438 & 0.3428 & 0.3102 & 0.3365 & 0.3450 & 0.3010 & 0.3067 \\
\hline Liaoning & 0.8963 & 0.8722 & 0.8520 & 0.8475 & 0.8643 & 0.8736 & 0.9029 & 0.8801 & 0.7492 & 0.6955 \\
\hline Neimenggu & 0.8857 & 0.7506 & 1.2416 & 1.1977 & 1.0888 & 0.8877 & 0.9250 & 0.8281 & 0.8841 & 1.0330 \\
\hline Ningxia & 0.6617 & 0.6166 & 0.9029 & 0.6049 & 0.6792 & 0.5710 & 0.5833 & 0.6047 & 0.6411 & 0.5043 \\
\hline Qinghai & 0.4839 & 0.4385 & 0.4494 & 0.4602 & 0.4302 & 0.4070 & 0.3762 & 0.3164 & 0.3172 & 0.2761 \\
\hline Shandong & 0.1086 & 0.1026 & 0.0721 & 0.0687 & 0.0672 & 0.0625 & 0.0614 & 0.0604 & 0.0543 & 0.0297 \\
\hline Shanxi & 0.1392 & 0.1391 & 0.1734 & 0.1781 & 0.2170 & 0.2290 & 0.1093 & 0.1440 & 0.1468 & 0.1204 \\
\hline Shaanxi & 0.1627 & 0.1549 & 0.1723 & 0.1885 & 0.1773 & 0.1736 & 0.1271 & 0.1259 & 0.1130 & 0.0955 \\
\hline Shanghai & 0.4484 & 0.5240 & 0.7923 & 0.6103 & 0.7047 & 0.5939 & 0.8168 & 1.2891 & 0.6655 & 0.4414 \\
\hline Sichuan & 0.1161 & 0.1020 & 0.0961 & 0.1011 & 0.0849 & 0.0715 & 0.0597 & 0.0631 & 0.0539 & 0.0467 \\
\hline Tianjin & 0.1650 & 0.1491 & 0.1507 & 0.1456 & 0.1906 & 0.1995 & 0.2559 & 0.2636 & 0.1801 & 0.1625 \\
\hline Xizang & 0.1299 & 0.1343 & 0.1386 & 0.1710 & 0.1526 & 0.1487 & 0.1392 & 0.2189 & 0.1941 & 0.1323 \\
\hline Xinjiang & 0.9266 & 0.7643 & 0.7988 & 0.6511 & 0.7274 & 0.6180 & 0.7754 & 0.7202 & 0.7797 & 0.9059 \\
\hline Yunnan & 0.3598 & 0.3386 & 0.3797 & 0.3632 & 0.3764 & 0.3034 & 0.1741 & 0.3413 & 0.2281 & 0.1639 \\
\hline Zhejiang & 0.0931 & 0.0767 & 0.0534 & 0.0495 & 0.0470 & 0.0433 & 0.0371 & 0.0340 & 0.0311 & 0.0161 \\
\hline Chongqing & 0.0845 & 0.0730 & 0.0677 & 0.0834 & 0.0711 & 0.0706 & 0.0774 & 0.0849 & 0.0583 & 0.0460 \\
\hline
\end{tabular}

progress variable, and $d Q / d A>0 . K$ refers to capital, $L$ refers to labor, and $\alpha$ and $\beta$ refer to the elasticity coefficient of capital and labor output, respectively. $r$ refers to the interest rate (considering the consistent interest rate set by banks over the country, it can be set that $\left.r_{1}=r_{2}=r_{3}=r\right)$. $w$ refers to wage. The net output of industry $i$ is $Y_{i}=A_{i} K_{i}^{\alpha} L_{i}^{\beta}-\left(r K_{i}+w_{i} L_{i}\right)$. Assuming that total tax revenue of industry $i$ is $T_{i}$, the net output of industry $i$ will be $Y_{i}=A_{i} K_{i}^{\alpha} L_{i}^{\beta}-r K_{i}-w_{i} L_{i}-T_{i}$. If the total tax revenue $T=T_{1}+T_{2}+T_{3}, Y_{i}=f\left(A_{i}, K_{i}, L_{i}, T_{i}, T\right)$, where $T=g_{1}(m t b), Y_{i}=g_{2}(v a t, b t, r t, t p, c s, i s, D), K_{i}=$ $g_{3}(c i t), L_{i}=g_{4}(i i t)$, and $T_{i}=g_{5}\left(t_{i}\right)$. It can be drawn that

$$
\begin{aligned}
\mathrm{IDH} & =s_{1}\left(m t b, v a t, b t, r t, c i t, i i t, t_{i}, t p, c s, i s, D\right) \\
\mathrm{IDR} & =s_{2}\left(m t b, v a t, b t, r t, c i t, i i t, t_{i}, t p, c s, i s, D\right)
\end{aligned}
$$

in which IDH and IDR are upgrading of industrial structure and rationalization of industrial structure, respectively. And the dependent variables are macrotax burden $(m t b)$, value added tax (vat), business tax $(b t)$, resource tax $(r t)$, corporate income tax (cit), individual income tax (iit), tax burden on the secondary industry $\left(t_{2}\right)$, tax burden on the tertiary industry $\left(t_{3}\right)$, technology progress $(t p)$, consumption structure (cs), investment structure (is), and regional differences dummy variables $(D)$, respectively.

Accordingly, a static empirical model is designed as follows; we will consider the dynamic and nonlinear cases in the future [14-17]:

$$
l y_{i t}=\beta_{0}+\sum_{j=1}^{m} \beta^{j} l x_{i t}^{j}+u_{i}+\varepsilon_{i t},
$$

where $l y_{i t}$ is the dependent variable at time $t$ in region $i . l x_{i t}^{j}$ denotes the independent variable $j$ at time $t$ in region $i . m$ refers to the number of independent variables $\beta_{0}$ denoting the constant coefficient. $\beta^{j}$ denotes the coefficient of the independent variable $j . u_{i}$ is the regional individual effect (if $u_{i}$ is fixed effect, then we assume that $\sum_{i=1}^{n} u_{i}=0$ in order to 


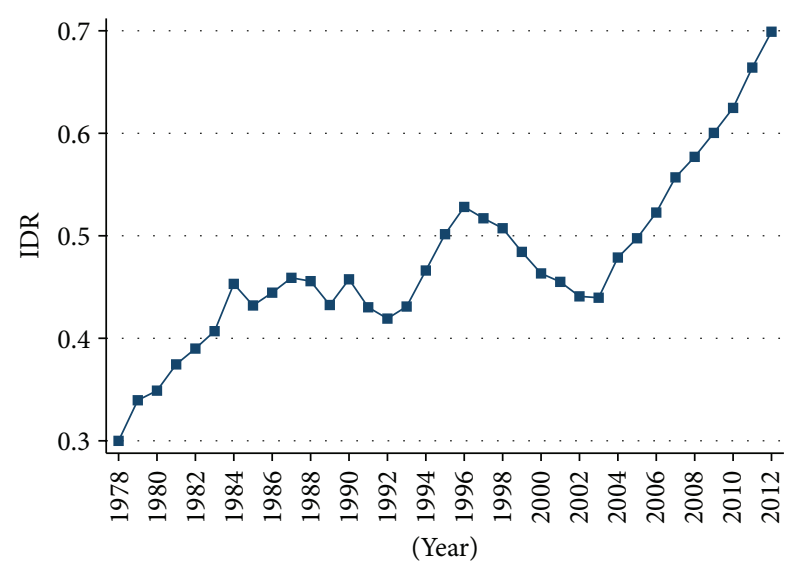

FIGURE 2: Rationalization of the industrial structure in China from 1978 to 2012.

avoid dummy trap). $\varepsilon_{i t}$ is the residual term at time $t$ in region $i$. The independent variable selected is subject to adjustment if needed by the study. Details are given in the text below.

4.2. Selection of Index for Empirical Study. According to [1821], the index selected in the empirical study includes the following: (1) explained variable is represented by the said upgrading and rationalization of industrial structure and descriptions are not given herein; (2) in view of industry, tax arrangement may be classified into turnover tax (such as value added tax and business tax), income tax (such as corporate income tax and individual income tax), and resource tax by object of taxation; (3) tax burden may be classified by industrial view into macrotax burden and property tax; (4) control variables include technology progress, consumption structure, and investment structure; and (5) the last is dummy variable of regional differences. The indexes are analyzed in Table 3.

4.3. Statistical Description of Explanatory Variables. Table 4 gives a statistical description to the average and standard deviation of all of the major explanatory variables of 31 province samples from 2003 to 2012. The average statistics reflect the mean level of variable sample data, while standard deviation indicates the degree of dispersion of variable data.

The average of macrotax burden $m t b$ variable tends to grow with low speed, while variance appears in rise and then in drop, indicating that macrotax burden gains an overall rise. The difference among provinces comes in an inverted$\mathrm{U}$ shape. The average of corporate income tax variable cit tends to increase with high speed, and the provincial gap (variance) is constantly broadened. The average of individual income tax variable iit tends to increase with high speed, and the provincial gap (variance) is constantly broadened. Slight variation is seen in the technology progress variable tp, and so do provincial differences. The resource tax variable $r t$ tends to increase with high speed, and the provincial gap (variance) is constantly broadened. The average of intermediate demand VAT variable vat tends to increase with high speed, and the provincial gap (variance) is constantly broadened. The business tax $b t$ of service and property sales demand tends to increase with high speed, and the provincial gap (variance) is constantly broadened. The consumption structure variable cs tends to increase; however, the growth rate is low, and the provincial gap (variance) tends to appear in identical broadening. The average of investment structure variable is tends to drop with low speed, and the provincial gap (variance) comes with a U-shape change. Averages of the tax on the secondary industry $t_{2}$ and the tertiary industry $t_{3}$ tend to increase with high speed, and the provincial gaps (variance) are also constantly broadened.

All independent variables other than dependent variables and dummy variables are logarithmic-based to eliminate and reduce unit difference and heteroskedasticity of indexes for different data during empirical study.

\section{Analysis of Empirical Study Results}

In this section, panel data of relevant index in 2003-2012 will be based to take empirical analysis of influence of tax arrangements to upgrading and rationalization of industrial structure in China. We check the stationarity of the variables using nonstationary panel data methods [22-27]; in particular, according to $[22,24]$, stationarity tests for series should be conducted before performing the panel regression; otherwise the regression may be spurious and this will result in misleading conclusions. And according to the Monte Carlo comparisons by $[25,26]$, the second-generation panel unit root tests proposed by Bai and $\mathrm{Ng}$ [24] and Pesaran [28] are robust relatively, so we choose them in our empirical study. We found that both tests reject the null of unit root for the variables lidh, lidr, lmtb, lvat, lbt, lcit, liit, lrt, lt $t_{2}, l_{3}, l_{t} p, l c s$, and $l i s$ and are statistically significant at the $10 \%$ significance level, so we conclude that these variables are stationary.

5.1. Empirical Analysis of Influence of Tax Arrangements to Upgrading of Industrial Structure. As shown in Table 5, Model I and Model II empirically analyze the influence on upgrading of industrial structure by macrotax burden, income tax, resource tax, technical progress, and regional difference. Considering a correlation in variables of corporate income tax and individual income tax, Model II will not include corporate income tax variables while Model I will not include individual income tax variables. Model III empirically analyzes the influence on upgrading of industrial structure by macrotax burden, turnover tax, consumption, and investment structure. Models IV and V intend to take income tax, turnover tax, macrotax burden, and relevant controlling variables into the empirical analysis. However, while the variable election differs due to a correlation of variables, Model VI empirically analyzes the influence on upgrading of industrial structure by macrotax burden and property tax.

Empirical analysis is as follows:

(1) The macrotax burden variables show a U-type influence path to the upgrading of industrial structure which is highly significant. The impact factor of quadratic term is between 0.323 and 0.438 and all 


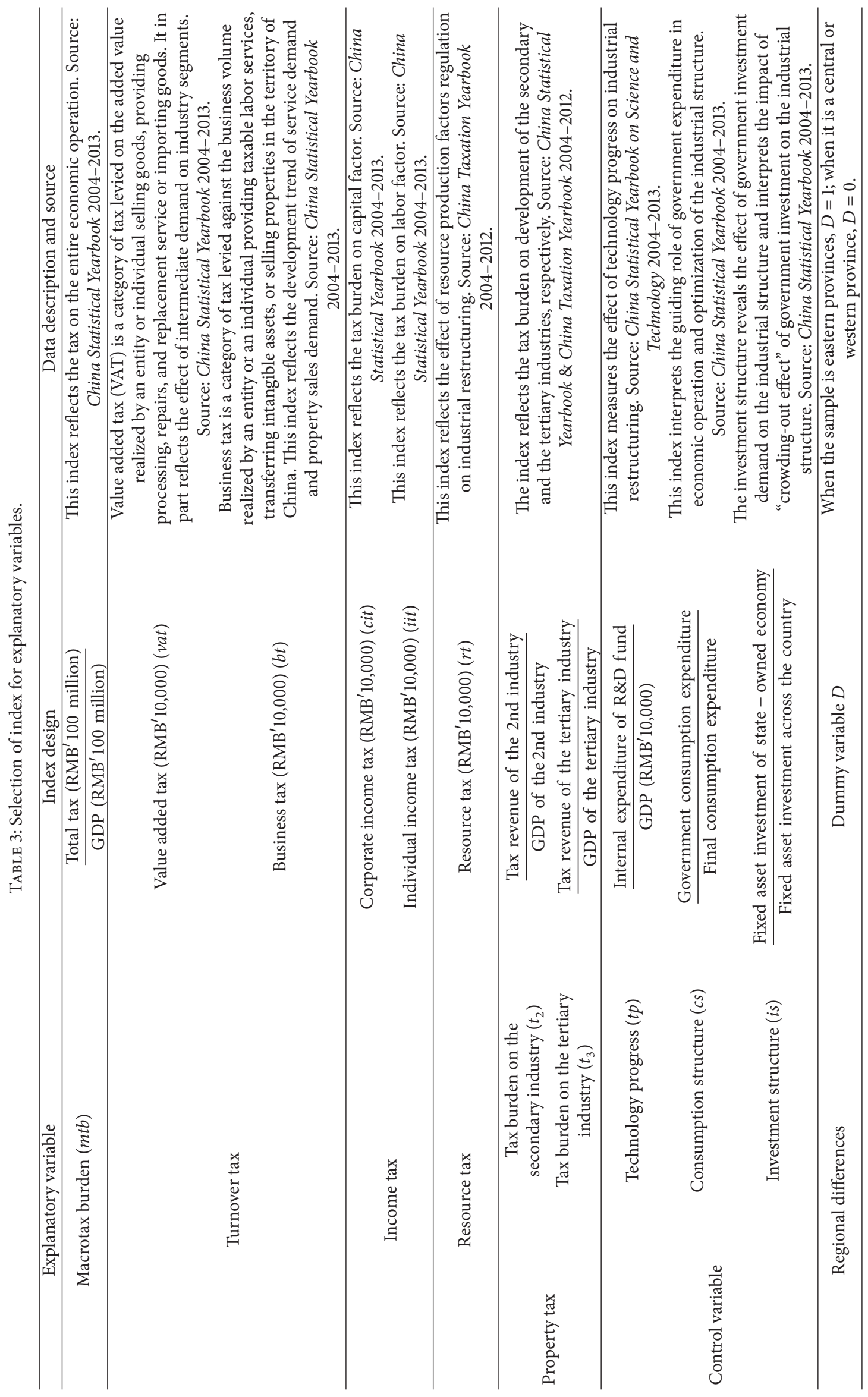


TABLE 4: Statistical description.

\begin{tabular}{|c|c|c|c|c|c|c|c|c|c|c|c|}
\hline \multirow{2}{*}{\multicolumn{2}{|c|}{ Variable }} & \multicolumn{10}{|c|}{ Year } \\
\hline & & 2003 & 2004 & 2005 & 2006 & 2007 & 2008 & 2009 & 2010 & 2011 & 2012 \\
\hline \multirow{2}{*}{$m t b$} & Mean & 0.1235 & 0.1301 & 0.1364 & 0.1439 & 0.1568 & 0.1623 & 0.1599 & 0.1652 & 0.1746 & 0.1854 \\
\hline & Variance & 0.0667 & 0.0699 & 0.0749 & 0.0824 & 0.1013 & 0.1003 & 0.0946 & 0.0895 & 0.0952 & 0.0974 \\
\hline \multirow{2}{*}{ cit } & Mean & 336614 & 443013 & 563194 & 704032 & 1010416 & 1290993 & 1263791 & 1628507 & 2176226 & 2442452 \\
\hline & Variance & 433527 & 566827 & 692390 & 830190 & 1210965 & 1578263 & 1450079 & 1847506 & 2304911 & 2450694 \\
\hline \multirow{2}{*}{ iit } & Mean & 182983 & 224135 & 270313 & 316626 & 410897 & 480026 & 510496 & 623969 & 780987 & 750849 \\
\hline & Variance & 219283 & 267480 & 321890 & 385118 & 497090 & 596669 & 630681 & 748404 & 910436 & 897732 \\
\hline \multirow{2}{*}{$t p$} & Mean & 0.0029 & 0.0026 & 0.0027 & 0.0025 & 0.0026 & 0.0026 & 0.0029 & 0.0028 & 0.0026 & 0.0028 \\
\hline & Variance & 0.0053 & 0.0049 & 0.0051 & 0.0046 & 0.0048 & 0.0047 & 0.0050 & 0.0053 & 0.0049 & 0.0051 \\
\hline \multirow{2}{*}{$r t$} & Mean & 27765 & 32934 & 47400 & 66809 & 87049 & 100587 & 109111 & 134701 & 192210 & 276051 \\
\hline & Variance & 32764 & 34919 & 49282 & 69588 & 84807 & 92512 & 98673 & 123631 & 191139 & 288282 \\
\hline \multirow{2}{*}{ vat } & Mean & 584190 & 711107 & 852975 & 1031090 & 1247620 & 1451347 & 1472664 & 1676216 & 1932023 & 2173277 \\
\hline & Variance & 569205 & 674559 & 786487 & 965633 & 1167868 & 1336011 & 1417941 & 1551903 & 1701475 & 2015463 \\
\hline \multirow{2}{*}{$b t$} & Mean & 892763 & 1119672 & 1323489 & 1602636 & 2057905 & 2385254 & 2853831 & 3549862 & 4356271 & 5013843 \\
\hline & Variance & 985239 & 1234838 & 1423919 & 1664198 & 2133788 & 2366498 & 2688985 & 3108735 & 3609470 & 4055253 \\
\hline \multirow{2}{*}{$c s$} & Mean & 0.4498 & 0.4589 & 0.4316 & 0.4395 & 0.4784 & 0.4875 & 0.4746 & 0.4787 & 0.4764 & 0.4796 \\
\hline & Variance & 0.1824 & 0.1849 & 0.1835 & 0.1590 & 0.2664 & 0.2679 & 0.2586 & 0.2351 & 0.2580 & 0.2783 \\
\hline \multirow{2}{*}{ is } & Mean & 0.4492 & 0.4085 & 0.4046 & 0.3854 & 0.3625 & 0.3705 & 0.3929 & 0.3783 & 0.3442 & 0.3081 \\
\hline & Variance & 0.1348 & 0.1240 & 0.1244 & 0.1090 & 0.1098 & 0.1233 & 0.1285 & 0.1289 & 0.1381 & 0.1254 \\
\hline \multirow{2}{*}{$t_{2}$} & Mean & 3411300 & 4315582 & 5177724 & 6201992 & 7728695 & 9089690 & 9819895 & 11981414 & 14693596 & 16314621 \\
\hline & Variance & 3234406 & 4006410 & 4597806 & 5491501 & 6906824 & 7957872 & 8678890 & 10420730 & 12431456 & 13289645 \\
\hline \multirow{2}{*}{$t_{3}$} & Mean & 2348154 & 2943225 & 3605911 & 4511797 & 6235886 & 7665066 & 8534221 & 10466289 & 13209027 & 16072604 \\
\hline & Variance & 3177114 & 3979230 & 4912740 & 6231402 & 9288148 & 10600913 & 11495582 & 12474978 & 15329544 & 17794101 \\
\hline
\end{tabular}

passed the inspection of $1 \%$ significance level. The impact factor of primary term is between 1.381 and 1.873; all passed the inspection of $1 \%$ significance level. When the macrotax burden keeps increasing, tax burden on tertiary industry will increase as well while the upgrading of industrial structure tends to decline; since then, with financial income increased, governmental departments will constantly increase constructing investment into infrastructures and improve supply of relevant public goods, prepare the rules and regulations on market environment and legal system which contributes to the development of tertiary industry, and benefit upgrading of industrial structure.

(2) Impact Path of Turnover Tax. The VAT variable vat shows tax arrangements for intermediate products needs and a U-type impact to the upgrading of industrial structure. The quadratic term factor of variable vat in Model III and Model IV was positive and primary term negative. We can see from the results that the increase of intermediate products will affect upgrading of industrial structure by U-path. The business tax variable $b t$ shows tax arrangements for service and real estate sales needs whose quadratic term factor in Model III and Model V was positive and the primary term factor was negative, which means that the increase of taxes on service and real estate sales needs will affect upgrading of industrial structure by U-path.

(3) Impact Path of Income Tax. Model I results have shown that variables of corporate income tax showed a U-path to industrial structure upgrading (with a quadratic term factor 0.013 and primary term factor -0.383 ) which is very significant (both quadratic and primary terms passed $1 \%$ significance level inspection). Model II results show that individual income tax showed a U-path to industrial structure upgrading (with a quadratic term factor 0.016 and primary term factor -0.432) which is very significant (both quadratic and primary terms passed the $1 \%$ significance level inspection). When the income tax of production factors increased in early period, the cost increases borne by tertiary industry count against the industrial structure upgrading (as said in the above theoretical analysis conclusion, the tax collection to production factors such as labor and capital in tertiary industry will go against the industrial structure upgrading). Then, with financial income increased, the government will optimize the market environment and legal system for development of tertiary industry guided by "economical service" while the production factors in secondary industry still assume tax burden (as said in the above theoretical analysis, the tax collection to production factors such as labor 
TABLE 5: Empirical analysis of influence of tax arrangements to IDH.

\begin{tabular}{|c|c|c|c|c|c|c|c|}
\hline \multirow{2}{*}{ Path } & \multirow{2}{*}{ Variables } & \multicolumn{5}{|c|}{ lidh } & \multirow[b]{2}{*}{ Model VI } \\
\hline & & Model I & Model II & Model III & Model IV & Model V & \\
\hline \multirow{2}{*}{ Macrotax } & $\operatorname{lm} t b^{2}$ & $\begin{array}{c}0.438^{* * *} \\
(6.81)\end{array}$ & $\begin{array}{c}0.393^{* * *} \\
(5.76)\end{array}$ & $\begin{array}{c}0.364^{* * *} \\
(6.27)\end{array}$ & $\begin{array}{c}0.323^{* * *} \\
(5.30)\end{array}$ & $\begin{array}{c}0.371^{* * *} \\
(4.73)\end{array}$ & $\begin{array}{c}0.375^{* * *} \\
(6.33)\end{array}$ \\
\hline & $\operatorname{lm} t b$ & $\begin{array}{c}1.873^{* * *} \\
(7.22)\end{array}$ & $\begin{array}{c}1.632^{* * *} \\
(6.17)\end{array}$ & $\begin{array}{c}1.570^{* * *} \\
(7.12)\end{array}$ & $\begin{array}{c}1.381^{* * *} \\
(5.73)\end{array}$ & $\begin{array}{c}1.588^{* * *} \\
(5.28)\end{array}$ & $\begin{array}{c}1.596^{* * *} \\
(7.12)\end{array}$ \\
\hline \multirow{4}{*}{ Turnover tax } & lvat $^{2}$ & & & $\begin{array}{l}0.013 \\
(0.93)\end{array}$ & $\begin{array}{l}0.004 \\
(0.29)\end{array}$ & & \\
\hline & lvat & & & $\begin{array}{c}-0.487 \\
(-1.35)\end{array}$ & $\begin{array}{l}-0.250 \\
(-0.64)\end{array}$ & & \\
\hline & $l b t^{2}$ & & & $\begin{array}{l}0.012 \\
(0.91)\end{array}$ & & $\begin{array}{l}0.003 \\
(0.15)\end{array}$ & \\
\hline & $l b t$ & & & $\begin{array}{l}-0.249 \\
(-0.70)\end{array}$ & & $\begin{array}{l}-0.097 \\
(-0.21)\end{array}$ & \\
\hline \multirow{4}{*}{ Income tax } & $l c i t^{2}$ & $\begin{array}{c}0.013^{* * *} \\
(3.42)\end{array}$ & & & $\begin{array}{l}0.015 \\
(1.60)\end{array}$ & & \\
\hline & lcit & $\begin{array}{c}-0.383^{* * *} \\
(-3.61)\end{array}$ & & & $\begin{array}{l}-0.331 \\
(-1.43)\end{array}$ & & \\
\hline & $l i i t^{2}$ & & $\begin{array}{c}0.018^{* * *} \\
(3.39)\end{array}$ & & & $\begin{array}{l}0.021 \\
(1.32)\end{array}$ & \\
\hline & liit & & $\begin{array}{c}-0.432^{* * *} \\
(-3.27) \\
\end{array}$ & & & $\begin{array}{c}-0.470 \\
(-1.30) \\
\end{array}$ & \\
\hline Resource tax & $l r t$ & $\begin{array}{r}-0.006 \\
(-0.31) \\
\end{array}$ & $\begin{array}{c}-0.038^{* *} \\
(-2.41) \\
\end{array}$ & & & $\begin{array}{r}-0.023 \\
(-1.15) \\
\end{array}$ & \\
\hline \multirow{4}{*}{ Property tax } & $l t_{2}^{2}$ & & & & & & $\begin{array}{l}0.009 \\
(0.86)\end{array}$ \\
\hline & $l t_{2}$ & & & & & & $\begin{array}{l}-0.513 \\
(-1.57)\end{array}$ \\
\hline & $l t_{3}^{2}$ & & & & & & $\begin{array}{l}0.007 \\
(0.73)\end{array}$ \\
\hline & $l t_{3}$ & & & & & & $\begin{array}{l}-0.062 \\
(-0.21)\end{array}$ \\
\hline \multirow{3}{*}{ Control variables } & $l t p$ & $\begin{array}{l}0.037 \\
(1.42)\end{array}$ & $\begin{array}{l}0.028 \\
(1.07)\end{array}$ & & $\begin{array}{l}0.030 \\
(1.19)\end{array}$ & & \\
\hline & $l c s$ & & & $\begin{array}{l}-0.010 \\
(-0.23)\end{array}$ & $\begin{array}{c}-0.007 \\
(-0.16)\end{array}$ & $\begin{array}{l}-0.015 \\
(-0.32)\end{array}$ & \\
\hline & lis & & & $\begin{array}{c}0.102^{*} \\
(1.95) \\
\end{array}$ & $\begin{array}{r}0.096^{*} \\
(1.85) \\
\end{array}$ & $\begin{array}{l}0.076 \\
(1.36) \\
\end{array}$ & \\
\hline Regional differences & $D$ & $\begin{array}{l}0.083 \\
(0.98) \\
\end{array}$ & $\begin{array}{l}0.018 \\
(0.21) \\
\end{array}$ & $\begin{array}{c}0.118^{*} \\
(1.78)\end{array}$ & $\begin{array}{c}0.118 \\
(1.60) \\
\end{array}$ & $\begin{array}{l}0.052 \\
(0.59)\end{array}$ & $\begin{array}{l}0.077 \\
(1.34) \\
\end{array}$ \\
\hline Constant & C & $\begin{array}{c}4.707^{* * *} \\
(6.21)\end{array}$ & $\begin{array}{c}4.544^{* * *} \\
(5.49)\end{array}$ & $\begin{array}{c}6.915^{* * *} \\
(5.39)\end{array}$ & $\begin{array}{c}5.780^{* * *} \\
(3.81) \\
\end{array}$ & $\begin{array}{c}5.248^{* * *} \\
(3.33) \\
\end{array}$ & $\begin{array}{c}6.462^{* * *} \\
(4.87) \\
\end{array}$ \\
\hline \multirow{3}{*}{$R^{2}$} & Within & 0.2092 & 0.2039 & 0.2232 & 0.2322 & 0.2102 & 0.2380 \\
\hline & Between & 0.6092 & 0.6198 & 0.7034 & 0.6834 & 0.6504 & 0.7597 \\
\hline & Overall & 0.5530 & 0.5608 & 0.6390 & 0.6231 & 0.5837 & 0.6910 \\
\hline
\end{tabular}

$* * *, * *$, and $*$ indicate statistical significance at the $1 \%, 5 \%$, and $10 \%$ significance level, respectively. The $t$-statistics are given in parenthesis, $R^{2}$ is a measure of goodness of fit in model regression, $R^{2}$-within is the $R^{2}$ from the mean-deviated regression, and $R^{2}$-between is the square of correlation between $\bar{X}_{i} \hat{\beta}$ and $\bar{Y}_{i}$, and $R^{2}$-overall is the square of correlation between $X_{i t} \widehat{\beta}$ and $Y_{i t}$.

and capital in secondary industry will contribute to the industrial structure upgrading). Thus, the extent of industrial structure upgrading will be constantly improved.
(4) Impact Path of Resources Tax. Model I, Model II, and Model V results show that the increase of resource tax will increase the industrial development cost, which will go against the upgrading of industrial structure. 
(5) Impact Path of Industry Tax. Model VI results show that tax burden both in secondary and in tertiary industry presents a U-type impact path to upgrading of industrial structure. The tax burden increases in tertiary industry go against upgrading of industrial structure in early period while the guide of government benefits it in later period. The tax burden increases in secondary industry promote the intermediate product cost required by tertiary industry which goes against industrial structure upgrading in early period; since then, the increases of tax burden in secondary industry gathered production factors into tertiary industry, contributing to industrial structure upgrading.

\subsection{Empirical Analysis of Influence of Tax Arrangements to} Rationalization of Industrial Structure. As shown in Table 6, Model I and Model II empirically analyze the influence on rationalization of industrial structure by macrotax burden, income tax, and resource tax. Considering a correlation in variables of corporate income tax and individual income tax, Model II will not include corporate income tax variables while Model I will not include individual income tax variables. Model III empirically analyzes the influence on rationalization of industrial structure by macrotax burden and turnover tax relevant controlling variables. Model III excludes business variables $b t$ and VAT variables vat. Model V empirically analyzes the influence on rationalization of industrial structure by macrotax burden and property tax.

Specific empirical analysis results are as follows:

(1) The macrotax burden variables show a U-type effecting path to the rationalization of industrial structure which is highly significant. The impact factor of quadratic term is between 0.5 and 0.733 and all passed the inspection of $1 \%$ significance level; primary term factor is between 2.192 and 2.976; all passed $1 \%$ significance level inspection.

(2) Impact Path of Turnover Tax. The VAT variable vat shows an inverse $U$-influence on rationalization of industrial structure, of which quadratic term factor of vat in the model is negative $(-0.061)$ and primary term factor is positive (1.419); both passed $1 \%$ significance level inspection. The increases of intermediate products will contribute to improving the optimal allocation of production factors in market and therefore benefit rationalization of industrial structure. However, excessive tax collection will aggravate the industry burden and go against the rationalization of industrial structure. Model IV results show that $b t$ presents an inverse $U$-influence on rationalization of industrial structure, of which quadratic term factor of vat in model is positive $(-0.035)$ and primary term factor is negative (0.756); both passed $5 \%$ significance level inspection.

(3) Impact Path of Income Tax. Model I results have shown that variables of corporate income tax showed an inverse U-path to industrial structure rationalization (with a quadratic term factor -0.035 and primary term factor 0.844 ) which is very significant (both quadratic and primary terms passed the $1 \%$ significance level inspection). Model II results have shown that individual income tax showed an inverse U-path to industrial structure rationalization (with a quadratic term factor -0.058 and primary term factor 1.327) which is very significant (both quadratic and primary terms passed the $1 \%$ significance level inspection). The increases of labor and capital factor will contribute "bloated" corporate to simplify the production factor stock as well as allocation of production factors in rational departments and therefore benefit rationalization of industrial structure. However, excessive increases of production factor cost will enlarge the pressure for industrial development and the incongruity of production factor and industrial development will go against rationalization of industrial structure.

(4) Impact Path of Resources Tax. Model I and Model II results show that the increase of resource tax will increase the industrial development cost, which will go against the rationalization of industrial structure.

(5) Impact Path of Industry Tax. Model V results show that tax increases of secondary industry go against rationalization of industrial structure and present an inverse U-path to rationalization of industrial structure together with tax burden in tertiary industry. In the early stage, the tax burden increases in tertiary industry caused the production factors flow to profit sector, which contributes to rationalization of industrial structure. While in later period, the uncoordinated flow of production factors will go against the rationalization of industrial structure.

\section{Conclusions}

The paper assesses and analyzes the regional industry restructuring firstly from the upgrading and rationalization of industrial structure and then empirically analyzes the influence to upgrading and rationalization of industrial structure by macrotax burden, turnover tax, income tax, resource tax, industry tax burden, and relevant controlling variables. The conclusions are as follows.

(1) The variable of macrotax burden presents a U-path of influence on upgrading and rationalization of industrial structure. When macrotax burden increases constantly in early period, the tax burden of tertiary industry increases as well, while upgrading and rationalization of industrial structure tend to decline; since then, with financial income increased, governmental departments will constantly increase investment in infrastructures and improve supply of relevant public goods, prepare the rules and regulations on market environment and legal system which contributes to the development of tertiary industry, and benefit upgrading and rationalization of industrial structure. Affected by policy 
TABLE 6: Empirical analysis of influence of tax arrangements to IDR.

\begin{tabular}{|c|c|c|c|c|c|c|}
\hline \multirow{2}{*}{ Path } & \multirow{2}{*}{ Variable } & \multicolumn{3}{|c|}{ lidr } & \multirow[b]{2}{*}{ Model IV } & \multirow[b]{2}{*}{ Model V } \\
\hline & & Model I & Model II & Model III & & \\
\hline \multirow{2}{*}{ Macrotax } & $\operatorname{lm} t b^{2}$ & $\begin{array}{c}0.618^{* * *} \\
(4.78)\end{array}$ & $\begin{array}{c}0.733^{* * *} \\
(5.38)\end{array}$ & $\begin{array}{c}0.573^{* * *} \\
(4.54)\end{array}$ & $\begin{array}{c}0.500^{* * *} \\
(4.26)\end{array}$ & $\begin{array}{c}0.667^{* * *} \\
(5.38)\end{array}$ \\
\hline & $\operatorname{lm} t b$ & $\begin{array}{c}2.510^{* * *} \\
(4.68)\end{array}$ & $\begin{array}{c}2.835^{* * *} \\
(5.32)\end{array}$ & $\begin{array}{c}2.192^{* * *} \\
(4.49)\end{array}$ & $\begin{array}{c}2.231^{* * *} \\
(4.74)\end{array}$ & $\begin{array}{c}2.976^{* * *} \\
(6.29)\end{array}$ \\
\hline \multirow{4}{*}{ Turnover tax } & $l v a t^{2}$ & & & $\begin{array}{c}-0.061^{* * *} \\
(-4.17)\end{array}$ & & \\
\hline & lvat & & & $\begin{array}{c}1.419^{* * *} \\
(3.50)\end{array}$ & & \\
\hline & $l b t^{2}$ & & & & $\begin{array}{c}-0.035^{* * *} \\
(-2.78)\end{array}$ & \\
\hline & $l b t$ & & & & $\begin{array}{c}0.756^{* *} \\
(2.05) \\
\end{array}$ & \\
\hline \multirow{4}{*}{ Income tax } & $l c i t^{2}$ & $\begin{array}{c}-0.035^{* * *} \\
(-4.48)\end{array}$ & & & & \\
\hline & lcit & $\begin{array}{c}0.844^{* * *} \\
(3.88)\end{array}$ & & & & \\
\hline & $\operatorname{liit}^{2}$ & & $\begin{array}{c}-0.058^{* * *} \\
(-5.25)\end{array}$ & & & \\
\hline & liit & & $\begin{array}{c}1.327^{* * *} \\
(4.87)\end{array}$ & & & \\
\hline Resource tax & $l r t$ & $\begin{array}{c}-0.108^{* * *} \\
(-2.61)\end{array}$ & $\begin{array}{c}-0.105^{* * *} \\
(-3.20) \\
\end{array}$ & & & \\
\hline \multirow{3}{*}{ Property tax } & $l t_{2}$ & & & & & $\begin{array}{c}-0.276^{* * *} \\
(-3.12)\end{array}$ \\
\hline & $l t_{3}^{2}$ & & & & & $\begin{array}{c}-0.039^{* * *} \\
(-3.70)\end{array}$ \\
\hline & $l t_{3}$ & & & & & $\begin{array}{c}1.127^{* * *} \\
(3.25) \\
\end{array}$ \\
\hline \multirow[b]{2}{*}{ Control variables } & $l c s$ & & & $\begin{array}{l}0.148 \\
(1.57)\end{array}$ & $\begin{array}{l}0.122 \\
(1.32)\end{array}$ & \\
\hline & lis & & & $\begin{array}{c}0.196^{*} \\
(1.89)\end{array}$ & $\begin{array}{l}0.124 \\
(1.21)\end{array}$ & \\
\hline Regional differences & $D$ & & & $\begin{array}{l}0.235 \\
(0.72) \\
\end{array}$ & $\begin{array}{l}0.200 \\
(0.61)\end{array}$ & $\begin{array}{l}0.133 \\
(0.40) \\
\end{array}$ \\
\hline Constant & $C$ & $\begin{array}{c}-2.763^{*} \\
(-1.67)\end{array}$ & $\begin{array}{c}-5.214^{* * *} \\
(5.49)\end{array}$ & $\begin{array}{c}-7.234^{* *} \\
(-2.48)\end{array}$ & $\begin{array}{l}-2.460 \\
(-0.90)\end{array}$ & $\begin{array}{c}-2.217 \\
(-0.86)\end{array}$ \\
\hline \multirow{3}{*}{$R^{2}$} & Within & 0.3387 & 0.3532 & 0.3268 & 0.3559 & 0.3489 \\
\hline & Between & 0.0490 & 0.0258 & 0.1254 & 0.1817 & 0.1371 \\
\hline & Overall & 0.0698 & 0.0474 & 0.1397 & 0.1929 & 0.1528 \\
\hline
\end{tabular}

$* * *, * *$, and $*$ indicate statistical significance at the $1 \%, 5 \%$, and $10 \%$ significance level, respectively. The $t$-statistics are given in parenthesis. $R^{2}$ is a measure of goodness of fit in model regression, $R^{2}$-within is $R^{2}$ from the mean-deviated regression, and $R^{2}$-between is the square of correlation between $\bar{X}_{i} \widehat{\beta}$ and $\bar{Y}_{i}$, and $R^{2}$-overall is the square of correlation between $X_{i t} \widehat{\beta}$ and $Y_{i t}$.

cost, the influence on upgrading and rationalization of industrial structure by macrotax burden in west areas is more visible.

(2) The VAT variable vat shows tax arrangements for intermediate products needs and a U-type impact on the upgrading of industrial structure, meaning that the tax increases of intermediate products will affect advancement of industrial structure by U-path. The business tax variable bt shows tax arrangements for service and real estate sales needs; the variable (i.e., service and product tax) increases will affect upgrading of industrial structure by U-path. VAT (intermediate product tax) increases will contribute to an optimal allocation for production factors in market and thus benefit the rationalization of industrial structure. However, excessive tax collection will aggravate the industry burden and go against the rationalization of industrial structure. The $b t$ presents an inverse $U$-influence on rationalization of industrial structure. The control function of turnover tax as financial policies in east areas is more visible and has a more significant and visible impact path on upgrading of industrial 
structure. As a main area for labor output, the labor cost influence in middle-east areas will be more sensitive under the impact of tax shift due to turnover tax increase, and thus the impact of turnover tax to rationalization of industrial structure in this area will be more visible.

(3) The variables of corporate and individual income tax present a U-path influence on upgrading of industrial structure. When the income tax of production factors increased in early period, the cost increases borne by tertiary industry count against the industrial structure upgrading. Then, with financial income increased, the government will optimize the market environment and legal system for development of tertiary industry guided by "economical service" while the production factors in secondary industry still bore tax burden. Thus, the extent of industrial structure upgrading will be constantly improved. The income tax in middle-east areas presents an inverse U-path for impact on upgrading of industrial structure; this kind of alienation is in connection with economic actions to undertake industry transfers in middle areas.

The variables of corporate and individual income tax present an inverse $U$-path influence on rationalization of industrial structure. The increases of labor and capital factor will facilitate "bloated" enterprises to simplify the production factor stock as well as allocation of production factors in rational departments, accordingly benefiting the rationalization of industrial structure. However, excessive increases of production factor cost will enlarge the pressure for industrial development and the incongruity of production factor and industrial development will go against rationalization of industrial structure. But it presents an alienated U-path impact in east areas, due to rich production factors and strong flow ability within industries in east areas, and the alienation impact path is not at all surprising.

(4) The addition of resource tax will increase the industrial development cost, which will go against the rationalization of industrial structure. And the dependence on resources in middle-west areas is more visible than in east areas, and thus the negative impact on upgrading and rationalization of industrial structure by resource tax is more visible and distinct.

(5) Tax burdens in both secondary and tertiary industries present a U-type impact path on upgrading of industrial structure. The tax burden increases in tertiary industry go against upgrading of industrial structure in the early period while the guide of government favors it in later period. The tax burden increases in secondary industry promote the intermediate product cost required by tertiary industry which goes against industrial structure upgrading in early period; since then, the increases of tax burden in secondary industry gathered production factors into tertiary industry, contributing to industrial structure upgrading. The tax increases of secondary industry go against rationalization of industrial structure and tax burden increase in tertiary industry presents an inverse $\mathrm{U}$-path to rationalization of industrial structure. In the early stage, the tax burden increases in tertiary industry contribute to rationalization of industrial structure. However, it will go against the rationalization of industrial structure in the later.

\section{Competing Interests}

The authors declare that there are no competing interests regarding the publication of this paper.

\section{Acknowledgments}

This work was partially supported by the National Natural Science Foundation of China (Grants nos. 71540007 and 71333007) and Natural Science Foundation of Hunan Province (Grant no. 2016JJ4026).

\section{References}

[1] H. H. Zee, J. G. Stotsky, and E. Ley, "Tax incentives for business investment: a primer for policy makers in developing countries," World Development, vol. 30, no. 9, pp. 1497-1516, 2002.

[2] M. Salinger and L. H. Summers, "Tax reform and corporate investment: a microeconometric simulation study," in Behavioral Simulation Methods in Tax Policy Analysis, pp. 247-288, University of Chicago Press, 1983.

[3] D. Rajagopal and A. Shah, "A rational expectations model for tax policy analysis: an evaluation of tax incentives for the textile, chemical and pharmaceutical industries of Pakistan," Journal of Public Economics, vol. 57, no. 2, pp. 249-276, 1995.

[4] J. M. Cansino, M. D. P. Pablo-Romero, R. Román, and R. Yñiguez, "Tax incentives to promote green electricity: an overview of EU-27 countries," Energy Policy, vol. 38, no. 10, pp. 6000-6008, 2010.

[5] W. Li, "Impact of tax policy on transition of industry structure: analysis of demand ways," Taxation and Economy, vol. 144, no. 1, pp. 7-11, 2006.

[6] W. Li, "Analysis on tax policy and optimization of industrial structure from the aspect of supply," Taxation Research, vol. 248, no. 1, pp. 40-44, 2006.

[7] S. Ren, Y. Yuan, H. Wang, and F. Ji, "Research on the influence of sulfur tax on the industrial structure of Liaoning province under CGE model," Energy Procedia, vol. 5, pp. 2405-2409, 2011.

[8] C.X. Wang, "The expect of tax on industrial structure," Research on Financial and Economic Issues, vol. 296, no. 7, pp. 89-94, 2008.

[9] X. H. Xia, Y. Hu, A. Alsaedi, T. Hayat, X. D. Wu, and G. Q. Chen, "Structure decomposition analysis for energy-related GHG emission in Beijing: urban metabolism and hierarchical structure," Ecological Informatics, vol. 26, no. 1, pp. 60-69, 2015.

[10] X. Wang, Y. Hu, X. Xia, and Y. Deng, "Estimation of the treatment effects of ownership on the indirect financing of small- and medium-sized enterprises," Discrete Dynamics in Nature and Society, vol. 2014, Article ID 453458, 6 pages, 2014.

[11] Y. Xiao, S. Wang, J. J. Liu, J. Xiao, and Y. Hu, “Throughput estimation based port development and management policies analysis," Maritime Policy \& Management, vol. 43, no. 1, pp. 8497, 2016.

[12] L. P. Zhou, "Transformation of industrial structure adjustment in the mode of economic development," Jiangsu Social Sciences, vol. 31, no. 6, pp. 57-61, 2010.

[13] C. H. Gan, R. G. Zheng, and D. F. Yu, "An empirical study on the effects of industrial structure on economic growth and fluctuations in China," Economic Research Journal, vol. 57, no. 5, pp. 4-16, 2011. 
[14] Y. Hu, D. Guo, Y. Deng, and S. Wang, "Estimation of nonlinear dynamic panel data models with individual effects," Mathematical Problems in Engineering, vol. 2014, Article ID 672610, 7 pages, 2014.

[15] C. Huang, Z. Yang, T. Yi, and X. Zou, "On the basins of attraction for a class of delay differential equations with nonmonotone bistable nonlinearities," Journal of Differential Equations, vol. 256, no. 7, pp. 2101-2114, 2014.

[16] C. Huang, C. Peng, X. Chen, and F. Wen, "Dynamics analysis of a class of delayed economic model," Abstract and Applied Analysis, vol. 2013, Article ID 962738, 12 pages, 2013.

[17] Y. Hu, X. Xia, Y. Deng, and D. Guo, "Higher order mean squared error of generalized method of moments estimators for nonlinear models," Discrete Dynamics in Nature and Society, Article ID 324904, 8 pages, 2014.

[18] C. Huang, X. Yang, X. Yang, and H. Sheng, "An empirical study of the effect of investor sentiment on returns of different industries," Mathematical Problems in Engineering, vol. 2014, Article ID 545723, 11 pages, 2014.

[19] F. Wen, Z. He, X. Gong, and A. Liu, "Investors' risk preference characteristics based on different reference point," Discrete Dynamics in Nature and Society, vol. 2014, Article ID 158386, 9 pages, 2014.

[20] Z. Dai and F. Wen, "Robust CVaR-based portfolio optimization under a genal affine data perturbation uncertainty set," Journal of Computational Analysis \& Applications, vol. 16, no. 1, pp. 93103, 2014.

[21] Y. Xiao, Y. Liu, J. J. Liu, J. Xiao, and Y. Hu, "Oscillations extracting for the management of passenger flows in the airport of Hong Kong," Transportmetrica A: Transport Science, vol. 12, no. 1, pp. 65-79, 2016.

[22] F. Wen, Z. He, Z. Dai et al., "Characteristics of investors risk preference for stock markets," Economic Computation and Economic Cybernetics Studies and Research, vol. 3, pp. 235-254, 2014.

[23] Y. Hu, J. Xiao, Y. Deng, Y. Xiao, and S. Wang, "Domestic air passenger traffic and economic growth in China: evidence from heterogeneous panel models," Journal of Air Transport Management, vol. 42, pp. 95-100, 2015.

[24] J. Bai and S. Ng, "A PANIC attack on unit roots and cointegration," Econometrica, vol. 72, no. 4, pp. 1127-1177, 2004.

[25] Y. Hu, D. Guo, M. Wang, X. Zhang, and S. Wang, "The relationship between energy consumption and economic growth: evidence from China'S industrial sectors," Energies, vol. 8, no. 9, pp. 9392-9406, 2015.

[26] J. H. Lin, Y. Hu, M. J. Wang, and X. H. Xia, "A monte carlo comparison of panel unit root tests under factor structure," Applied Economics Letters, vol. 20, no. 3, pp. 288-291, 2013.

[27] Y. Hu, X. Xia, M. Wang, and Z. Chen, "The effects of crosssection dimension $n$ in panel co-integration test," Communications in Nonlinear Science and Numerical Simulation, vol. 15, no. 4, pp. 1019-1027, 2010.

[28] M. H. Pesaran, "A simple panel unit root test in the presence of cross-section dependence," Journal of Applied Econometrics, vol. 22 , no. 2, pp. 265-312, 2007. 


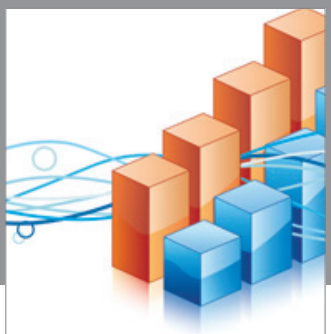

Advances in

Operations Research

vatem alat4

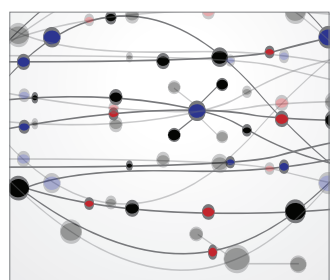

\section{The Scientific} World Journal
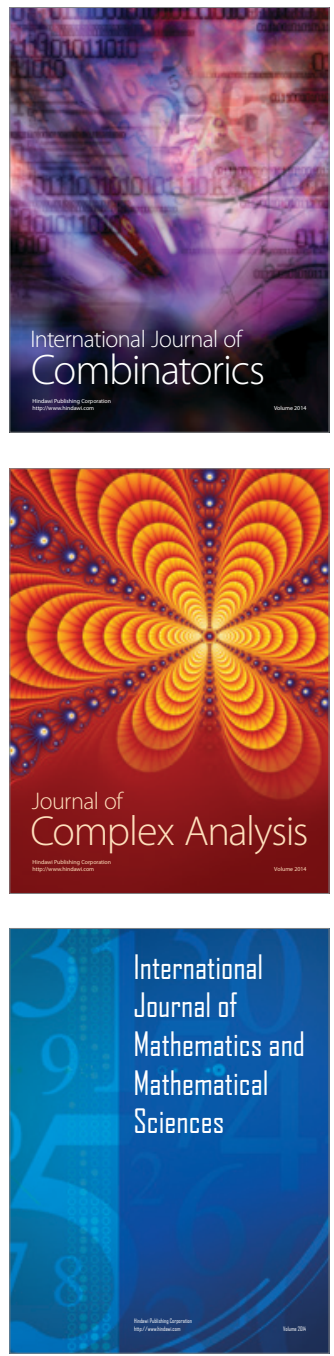
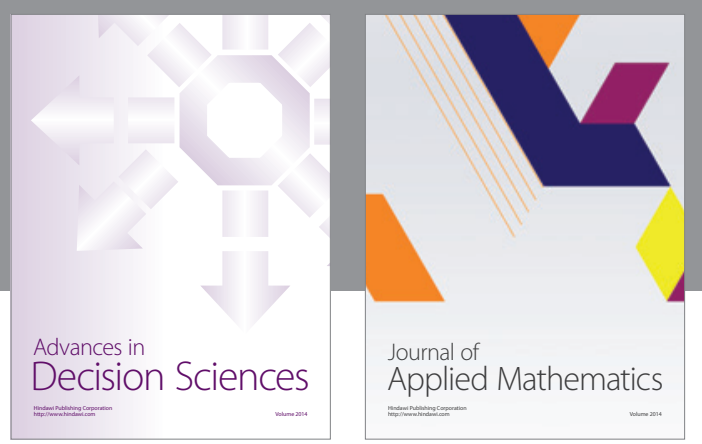

Algebra

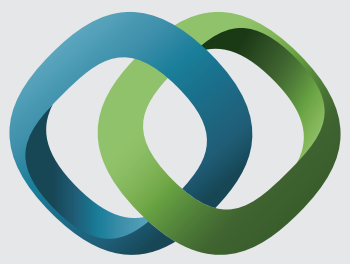

\section{Hindawi}

Submit your manuscripts at

http://www.hindawi.com
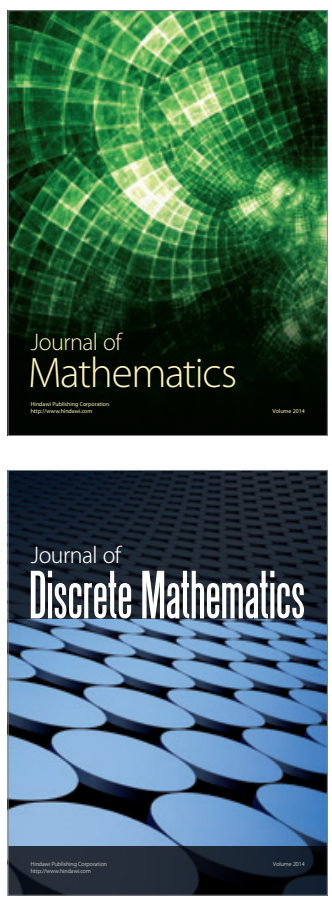

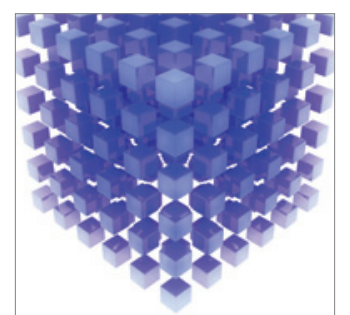

Mathematical Problems in Engineering
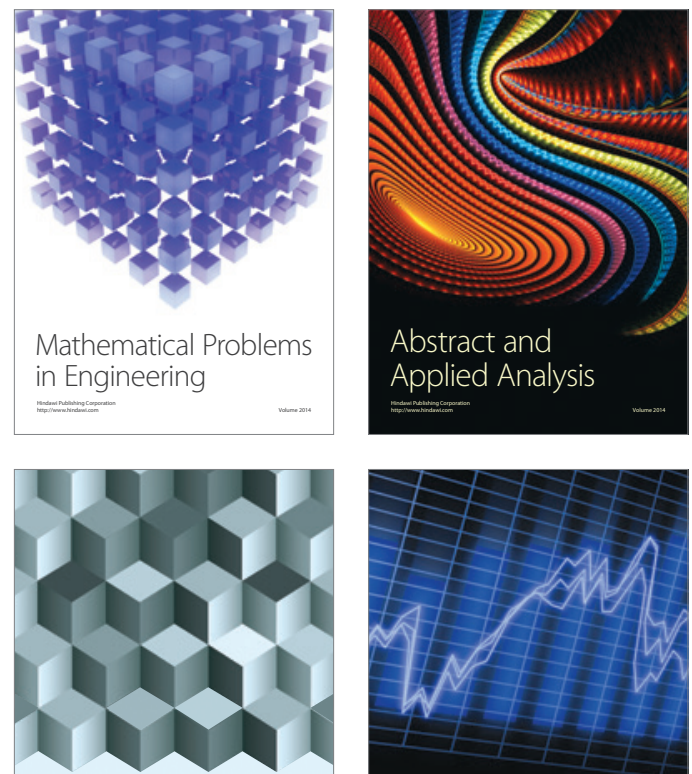

Journal of

Function Spaces

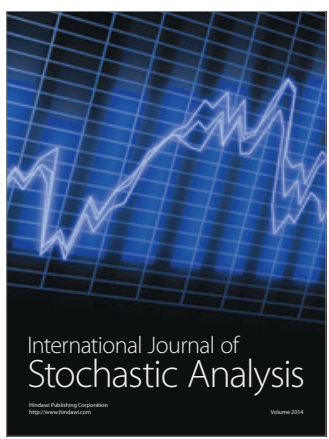

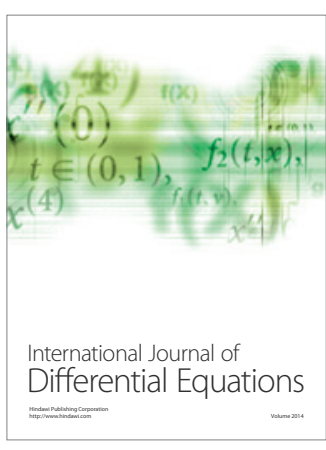
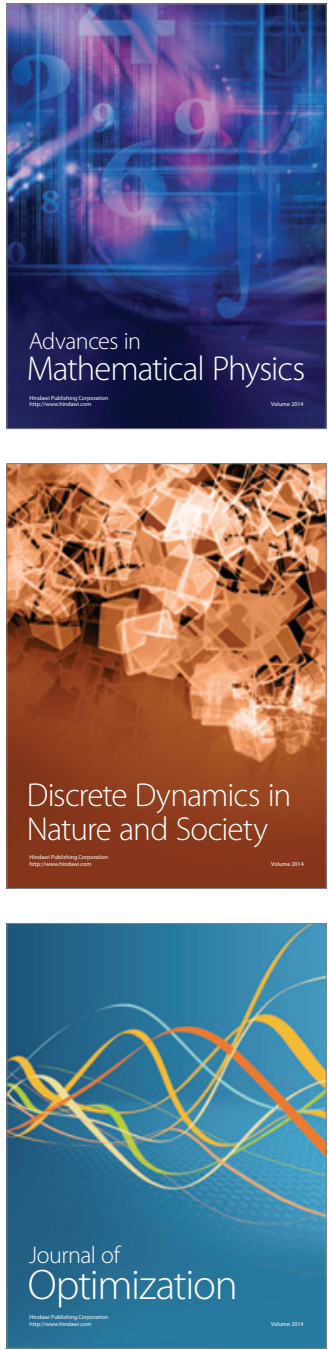